\title{
Pre-Implantation Conceptus and Maternal Uterine Communications: Molecular Events Leading to Successful Implantation
}

\author{
Kazuhiko IMAKAWA ${ }^{1)}$, Kyu-Tae CHANG ${ }^{2)}$ and Ronald K. CHRISTENSON ${ }^{3)}$ \\ 1) Implantation Research Group, Laboratory of Animal Breeding, Graduate School of \\ Agricultural and Life Sciences, The University of Tokyo, Tokyo 113-8657, Japan, ${ }^{2)}$ The Korea \\ Research Institute of Bioscience and Biotechnology, Daejon, 305-333, Korea, ${ }^{3)}$ USDA-ARS, \\ U.S. Meat Animal Research Center, Clay Center, NE 68933-0160, USA
}

\begin{abstract}
Implantation, a critical step for mammals in establishing pregnancy, requires successful completion of sequential events such as maternal uterine development, conceptus development and attachment, and placental formation. To reach the stage of placental formation, synchronized development of the conceptus and uterus throughout the implantation period is absolutely required. A number of factors expressed at the uterine endometrium and/or conceptus, which are associated with peri-implantation development, have been identified. In addition to a temporal and spatial expression of these factors, their roles in intra- and inter-cellular interactions make it difficult to fully understand physiological roles played during the critical period. This paper focuses on early conceptus development, maternal preparation for implantation and uterine-conceptus communication during the pre-implantation period, rather than the subsequent events such as conceptus attachment to the maternal endometrium. New aspects of pre-implantation processes are evaluated through simultaneous expressions of transcription factors as they possibly regulate the complex processes of implantation events in murine species and ruminant ungulates.

Key words: Pre-implantation period, ICM, Trophoblast, Implantation window, Maternal-conceptus communication
\end{abstract}

(J. Reprod. Dev. 50: 155-169, 2004)

U

nlike those vertebrates that are hatched from eggs, mammals nurture fetuses within the uterus. Beyond egg yolk, mammalian fetuses rely on the continuous supply of maternal nutrients and oxygen, resulting from the maintenance of an intimate relationship through the dynamic structure called the "placenta". Failures in implantation or a lack of sufficient placental development or functioning lead to conceptus losses. Such losses are commonly associated with in vitro fertilization procedures in humans and

Accepted for publication: January 15, 2004

Correspondence: K. Imakawa

(e-mail: akaz@mail.ecc.u-tokyo.ac.jp) livestock species of the agricultural industry.

Implantation is the process through which a developing conceptus attaches to the maternal endometrium. After successful fertilization, the first step in the peri-implantation period is the migration of the blastocysts from the oviduct into the uterus. As early as 3.5 day post coitus (d.p.c.) in the mouse, the blastocyst differentiates into inner cell mass (ICM) which later forms the embryo, and the trophoblast which later forms the placenta. When a mouse blastocyst reaches the implantation site, it subsequently hatches from the zona pellucida and starts to attach to the endometrium at 4.0-5.0 d.p.c. During this development period, the 
uterus in preparation to be receptive to the conceptus is in the critical stage called "implantation window", which is the only time the conceptus can attach to the endometrium. Even before the stage of direct attachment, biochemical communication is thought to exist and function between the uterine endometrium and the conceptus. This maternal-conceptus cross talk influences both pre-attachment conceptus development and attainment of uterine receptivity. Thus, only when the uterus and the conceptus develop in a synchronized manner, the attachment can occur between the trophectoderm cells and endometrium. The maternal-conceptus connection becomes closer when the conceptus invades the endometrium; then early placenta is formed between the uterus and conceptus, and substances vital for survival and further development of the embryo begin to be exchanged through this structure.

Differing from rodents and primates, the ruminant blastocyst undergoes a longer, up to two weeks, pre-attachment period. During this period, ruminants possibly require a longer duration for the establishment of maternal-conceptus communication, which may determine the outcome of implantation. Instead of establishing communication, the processes of active attachment and trophoblast invasion to maternal endometrium may be more important in rodents and primates when compared with that in ruminants. A thesis in this review is based on our hypothesis that conceptuses of ruminants go through closer and more distinct maternal-conceptus communication than those of rodents or primates during the preimplantation period.

Although the focus of implantation studies generally has been conceptus attachment and invasion to the maternal endometrium, in this paper, the progress of the conceptus and uterus and communication between them in the preimplantation period are evaluated. This is based on the hypothesis that these events are the starting point of successful implantation. A variety of molecules including adhesion, signaling, transcription, cell cycle and DNA replication proteins coordinate conceptus and uterine development, differentiation and structural formation during this critical phase. In particular, associations and potential interactions among endometrial and conceptus factors are reviewed and their molecular cascades of expressions during the implantation period are presented.

\section{Pre-implantation Development of the Conceptus}

After fertilization in the oviduct, the fertilized ovum moves toward the uterus while undergoing several cell divisions. As the morula reaches the uterus, the first differentiation, formation of the blastocyst occurs. The blastocyst, which contains a blastocoel, consists of two distinct types of cells: the trophectoderm, the outer layer of rapidly dividing cells and ICM, undifferentiated cuboidal cells. The ICM gives rise to the embryo plus extra-embryonic membranes such as allantois and amnion, while the trophectoderm contributes to the trophoblast layers of the placenta. After differentiation to ICM and trophoblast cells, the blastocyst hatches from the zona pellucida and acquires the ability to attach to the uterus. In rodents and primates, blastocysts start attachment and invasion shortly after the hatching whereas in ruminant ungulates, the blastocysts are free floating in the uterus for several days before rapid elongation on days 11 and 12 (day $0=$ day of estrus). At the end of this elongation the ruminant conceptus occupies almost the entire surface of the uterine luminal epithelia, during which non-specific and loose attachment of the trophoblasts to the endometrium takes place. After going through such physical and biochemical processes of elongation and loose association, the ruminant trophoblasts finally start their attachments to specialized regions, caruncles, of the uterine endometrium.

Transcription factors expressed in ICM or trophoblast lineages

The molecular events underlying the differentiation of distinct cell lineages, ICM and trophoblast, are still not well understood. It is generally believed that transcription factors play critical roles in promoting and driving this first differentiation. Numerous transcription factors are expressed in trophoblasts, including Rex-1 [1], GATA-3 [2], T-box gene Eomesodermin (Eomes) [3, 4], the caudal-related gene $\mathrm{Cdx}-2$ [5], activating protein 2 gamma (AP-2 $\gamma$ ) [6, 7], basic helix-loophelix (bHLH) gene Mash2 [8] and Hand1 [9], and Ets-2 [10]. The T-box gene Eomes and homeobox 
gene $\mathrm{Cdx}-2$ are required for early trophoblast development during the pre-implantation period $[11,12]$. AP- $2 \gamma$, Mash2, Hand1 and Ets-2 are involved in trophoblast development during the peri- and post-implantation periods [10, 13-15].

\section{Trophectodermal transcription factors involved in} blastocyst formation and implantation

A transcription factor, Eomes, is implicated as an important regulator of gastrulation in Xenopus [16], and its expression is also detected during early mouse development [3]. Expression of mouse Eomes is first detected in the trophectoderm cells of the blastocyst, and continues to be found in the extra-embryonic ectoderm of the early postimplantation embryo. Development of mouse conceptuses lacking the Eomes transcription factor is arrested at the blastocyst stage. Morphological analysis at 6.0 and 7.5 d.p.c. revealed that the development of conceptuses with mutated Eomes is arrested soon after implantation and organized embryonic or extra-embryonic structures are not formed. In blastocyst culture, mutant homozygotes did not exhibit trophectoderm outgrowths, although they hatched normally and maintained the typical blastocyst morphology until 7 days after the initiation of in vitro culture. In wild type mice, Eomes is only expressed in the trophectoderm during implantation, indicating that Eomes may be required for the differentiation of the trophoblast cell lineage [12].

A transcription factor, $\mathrm{Cdx}-2$, is detected in the epithelium of the adult mouse uterus as one of the homologues of Drosophila homeobox gene, caudal [17]. In the mouse, immunohistochemical analyses revealed that $C d x-2$ is expressed from 3.5 d.p.c. only in the trophectoderm of the blastocyst and later in placental tissues derived from the trophectoderm [5]. Cdx-2 null mutant blastocysts exist in the uterus immediately before implantation (3.5 d.p.c.), but the null mutant blastocyst cannot be detected right after the implantation period (5.5 d.p.c.) indicating that $\mathrm{Cdx}-2$ deficient blastocysts die between 3.5 and 5.5 d.p.c. and fail to implant successfully [11]. Thus, the homozygous mutant mouse conceptuses of $C d x-2$ gene show a similar phenotype to that of Eomes, suggesting that $\mathrm{Cdx}-2$ is also necessary for trophectoderm differentiation of blastocysts and for subsequent implantation.

Transcription factor AP- $2 \gamma$ is expressed in the trophectodermal cells prior to implantation and its expression continues in the trophoblast lineages throughout placental development [6, 7]. AP-2 $\gamma$ has been shown to regulate the genes for adenosine deaminase (ADA) [6, 18], human placental lactogen [19] and human chorionic gonadotropin- $\beta$ [20], which strongly suggests the role of AP- $2 \gamma$ in the regulatory program involving trophoblast cell gene expression. Mutation of the AP- $2 \gamma$ gene in the mouse conceptus shows its necessity in the early post-implantation period since homozygous mutant conceptuses die between 7.5 and 8.5 d.p.c. $[21,22]$, which is a little later than null mutants of Eomes or Cdx-2 gene. In support of these observations, defective development in embryonic and extra-embryonic structures is noted in histological sections from AP- $2 \gamma$ null mutant mouse conceptuses at 7.5 d.p.c. In addition, in vitro culture of the AP- $2 \gamma$ null blastocyst exhibits attachment but defective outgrowth of trophectoderm cells after 7 days in culture [21, 22]. Moreover, in AP-2 $\gamma$ mutant trophoblast cells, Cdx-2 and Eomes expression are significantly reduced or undetectable [21], suggesting that there is a direct association between the function of AP- $2 \gamma$ and the expression of $\mathrm{Cdx}-2$ or Eomes genes in extra-embryonic membranes.

Development in Hand 1 deficient mouse conceptuses is arrested by 8.0 d.p.c. with defects in trophoblast cell differentiation and those of Mash-2 die at 10.0 d.p.c. from placental failure [13-15]. $\mathrm{H} \beta$ 58 homozygous mutant conceptuses also show a trophoblastic defect from 7.5 d.p.c. and die at about 9.5 d.p.c. $[23,24]$, though the function of $\mathrm{H} \beta-58$ has not been definitively elucidated. Targeted deletion of the Ets-2 gene causes failure in trophoblast cell migration and differentiation at 7.0 d.p.c. and results in death of the conceptus before 9.0 d.p.c. [10]. While Ets-2 is expressed in many cell types in developing mouse conceptuses [25], it is also expressed in early trophoblast lineage from 7.0 d.p.c. Ets-2 null mouse conceptuses exhibit deficiencies in the expression of the matrix metalloproteinase-9 (MMP-9) gene, whose product is known as a trophoblast derived proteinase that degrades the extracellular matrix and matrices of endometrial epithelial and stromal cells, indicating that Ets-2 might control the degree of trophoblast invasion mediated by MMP-9.

As described above from murine experiments, several genes have been found to be trophoblast specific transcription factors. Different terms in arrested development exhibited by these mutant 


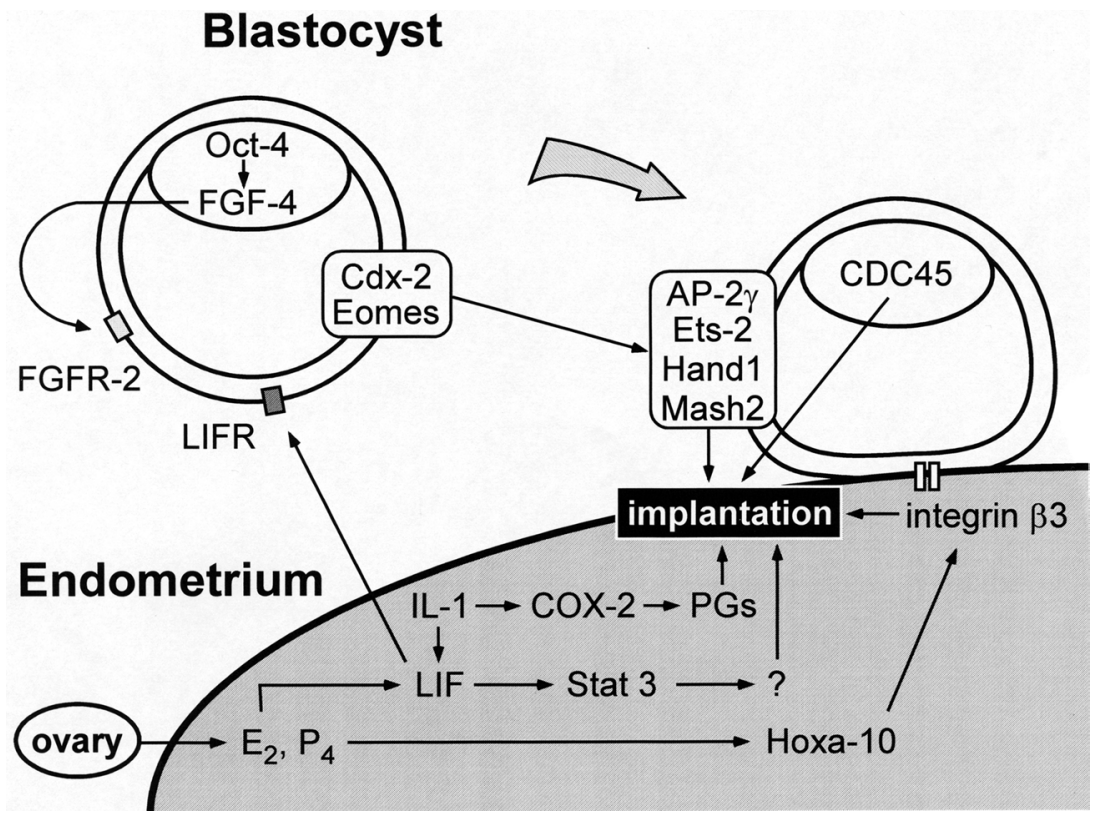

Fig. 1. Gene expression model during the early implantation period in the mouse. In the endometrium, ovarian $\mathrm{E}_{2}$ induces a cytokine, LIF, which activates Stat 3, resulting in the gene expression cascade required for the uterine preparation for implantation. Serum $\mathrm{E}_{2}$ and $\mathrm{P}_{4}$ modulate the transcription factor Hoxa-10 which up-regulates the integrin $\beta 3$ subunit, a cell adhesion molecule. IL-1 may be involved in PGs production through activation of COX-2 gene. Preimplantation blastocyst cells differentiate into ICM and trophoblast cells. In ICM, Oct- 4 and FGF-4 are required for maintaining pluripotency and there is strong evidence that FGF-4 is induced by Oct-4. FGF-4 also affects the trophoblast cell proliferation through a receptor, FGFR-2. Pre-implantation trophoblast cells express transcription factors such as Cdx-2 and Eomes, which may induce other transcription factors like AP-2, Ets-2, Hand1 and Mash2 involved in various aspects of implantation processes. DNA replication factor CDC45 also influences the degree of ICM cell proliferation in implantation processes.

mouse conceptuses lead us to propose the hypothesis: first transcription factors, Eomes and Cdx-2, influence trophectoderm cell differentiation, followed by sequential expression of transcription factors, Hand1, AP- $2 \gamma$, Ets-2, H $\beta-58$ and Mash2, all of which effect development of trophoblastic cells during the early post-implantation period, resulting in the induction of MMP-9 that regulates trophoblast invasion to the maternal endometrium in rodents. Nevertheless, simultaneous expression and interactions of these factors that regulate the trophoblast differentiation and implantation have not been well characterized.

Transcription factors involved in ICM differentiation

Trophoblast cells attach directly to the endometrium; however, ICM is known to be required for the maintenance of trophectoderm, indicating that both ICM and trophectoderm are involved in successful implantation. POU-domain transcription factor Oct-4, essential for the maintenance of pluripotency in the ICM, is expressed throughout oogenesis and preimplantation development, and its expression is only found in the ICM at the blastocyst stage [26, 27]. The absence of Oct- 4 in the mouse conceptus results in peri-implantation lethality from defective ICM development. Because Oct-4 null conceptuses die between 3.5 and 5.5 d.p.c., only traces of trophoblastic cells and decidual swellings are found in the endometrium. Homozygous Oct-4 deficient conceptuses cultured yield only trophoblast cells, but do not contain a recognizable ICM-derived structure. Inactivation of Oct-4 in 
embryonic stem (ES) cells reveals that Oct-4 appears to be indispensable for the self-renewing undifferentiated ES cell phenotype. Thus, Oct-4 null conceptuses develop to the blastocyst stage, but the ICM cells are not pluripotent and die, because only the cells of trophoblast lineage are detected. This indicates that Oct-4 is required for early ICM development [28].

In the absence of the ICM, trophoblast proliferation is not maintained in Oct- 4 deficient conceptuses due in part to a lack of fibroblast growth factor-4 (FGF-4) expression. FGF-4 is also expressed in the ICM of the murine blastocyst [29, 30]. Analyses of FGF-4 knockout mice, which have phenotypes similar to the Oct- 4 mutant, show the requirement of FGF-4 for early post-implantation development [31]. Before implantation (4.0 d.p.c.), FGF-4 null conceptuses exist in the uterus, but after the time of implantation (9.0 d.p.c.) no null mutant embryos exist although the endometrial deciduas are present. In fact, 4.0 d.p.c. FGF-4 null conceptuses appear morphologically normal but histological sections of the uterus show a lack of embryonic structures in FGF-4 null conceptuses at 6.0 and 7.0 d.p.c. FGF-4 null conceptuses cultured display severely impaired proliferation of the ICM, indicating that FGF-4 is essential for ICM development. Thus, both transcription factor Oct-4 and growth factor FGF-4, possibly in coordinated expression, are involved in differentiation and maintenance of ICM. The upstream region of the murine FGF-4 gene contains POU domain to which Oct- 4 binds and activates FGF- 4 gene transcription that is associated with another transcription factor Sox-2 [32, 33], suggesting that Oct-4 up-regulates FGF-4 expression resulting in ICM differentiation. Furthermore, FGF-4 is not only essential for the maintenance of ICM, but also is critical for trophectoderm proliferation and differentiation. On the other hand, FGF receptor 2 (FGFR-2) is expressed in both ICM and trophectoderm cells [34-36], consistent with a paracrine interaction of the ligand and receptor between ICM and trophectoderm [28, 37]. Null mutation of the FGFR-2 gene exhibits a similar phenotype as FGF-4 mutant conceptuses, which die soon after the time of implantation, resulting from defects in ICM differentiation around 4.5 d.p.c. and onward [38]. FGF-4 has also been shown to be critical in the maintenance of the trophoblast stem (TS) cells in vitro [39]. These observations indicate that Oct- 4 expressed in ICM of the blastocyst enhances the ICM expression of FGF-4, which affects both ICM and trophoblast development mediated through the FGFR-2 pathway. Thus, the differentiation of ICM and trophoblast cells during the process of implantation is regulated by means of factors like Oct-4, FGF-4 and FGFR-2.

Recently, DNA replication initiator CDC45 deficient mice were shown to be embryonically lethal [40]. CDC45 is an essential gene for the initiation of DNA replication in Saccharomyces cerevisiae [41-43]. A human homologue of CDC45 has been isolated, and the encoded protein has been shown to associate with human origin recognition complex (ORC) protein [44] or human minichromosome maintenance protein $(\mathrm{MCM})$ and a subunit of DNA polymerase $\alpha$ [45] in cultured cells. These results indicate that human CDC45 homologue has the same function as yeast CDC45, which also binds to the equivalent proteins and initiates DNA replication. The CDC45 null conceptuses in the uterus disappear soon after implantation between 3.5 d.p.c. and 7.5 d.p.c. CDC45 null blastocysts at 3.5 d.p.c. appear to be normal but in vitro culture of such blastocysts shows no proliferation of the ICM after attachment while trophoblast outgrowth appears normal. These results in CDC45 deficient blastocysts are similar to those of Oct- 4 or FGF-4 mutant mice, indicating the interrelationship of CDC45 with Oct4 or FGF-4. Interestingly, mouse conceptuses deficient in several other genes, which are expressed in the cell cycle, such as Chk-1, Brg-1, NEDD-8, and Mat-1, are also reported to die during the implantation period [46-49]. These observations provide a new insight into the importance of cell cycle control in ICM differentiation and implantation processes.

Factors discussed in this section may be studied individually, but the simultaneous expression and interactions of these molecules may be important for elucidating how blastocysts form and develop. It is now apparent that blastocyst formation is regulated by coordinated expression of sets of genes crucial to the progression to successful implantation. More researches focusing on detection of new factors and interactions of the genes so far identified are required to fully understand the implantation processes. 


\section{Preparation of the Uterus for Blastocyst Implantation}

Many studies have shown that the uterus during the tightly controlled period called the "implantation window" allows the conceptus to attach to the endometrium in ruminants, rodents and primates. Most mammalian females have estrous cycles during which the endometrium undergoes developmental changes. In the pregnant mouse, the uterus becomes receptive only on 4.5 d.p.c. (day of implantation) and by 5.5 d.p.c., the uterus becomes refractory and fails to respond to the presence of blastocysts. Several endometrial factors controlled by ovarian steroid hormones, estrogen and progesterone, are known to regulate uterine receptivity, resulting in successful implantation. In rodents and primates, the implantation window is established when estrogen affects the endometrium that has been under the influence of progesterone. If estradiol-17 $\beta\left(\mathrm{E}_{2}\right)$ levels are kept low during the 24 hours before the conceptus normally attaches, or if progesterone $\left(\mathrm{P}_{4}\right)$ is sustained at high levels, the mouse blastocyst remains in diapause (delayed implantation) [50]. Further, an embryo entering the uterus before it has been prepared by a $\mathrm{P}_{4}$ signal will not implant. Thus, $\mathrm{E}_{2}$ and $\mathrm{P}_{4}$ are thought to regulate uterine receptivity directly, though the regulatory mechanisms are not well characterized. The influences of $\mathrm{E}_{2}$ or $\mathrm{P}_{4}$ have been examined by deleting the estrogen receptor (ER) or progesterone receptor (PR). Male and female mouse conceptuses with a homozygous deletion of the ER or PR gene developed normally to adulthood, however, female homozygous mutant mice are sterile and show various aspects of reproductive failure [51, 52]. Since ER or PR null conceptuses can survive in the uteri of wild type mice, ovarian steroids do not seem to act directly on conceptuses. Therefore, it appears that some other important molecules, upregulated through uterine ER or PR, mediate the effect of these steroid hormones, resulting in the establishment of the implantation window.

\section{Transcription factor, Hoxa-10}

The homeobox gene, Hoxa-10, null mutant mice show female infertility resulting from defective conceptus implantation [53, 54]. Blastocysts from these mice implant normally when transferred to the uteri of wild-type mice, but blastocysts from wild type mice fail to implant in Hoxa-10 null mice. From these results, Hoxa-10 expressed by the uterine endometrium has been shown to be an essential factor for implantation. Uterine Hoxa-10 is regulated by $\mathrm{E}_{2}$ and $\mathrm{P}_{4}$ both in the mouse and the human $[55,56]$ and high levels of Hoxa-10 mRNA are found in the endometrium during the period of the implantation window $[53,56,57]$. Recently, human uterine Hoxa-10 was demonstrated to induce the expression of uterine epithelial $\beta 3$ integrin subunit [58], and a lack of its expression could be one possible mechanism by which sterility occurs in Hoxa-10 mutant mice. Conceptus attachment begins from interactions of the blastocyst with the endometrium, which are mediated through cell adhesion molecules such as the integrin family $[59,60]$. Integrins, glycoproteins that serve as receptors for extracellular matrix ligands and act as modulators of cellular function, are now one of the best-characterized immunohistochemical markers for uterine receptivity [61]. The $\beta 3$ integrin subunit exists in the uterine epithelium in the form of $\alpha \mathrm{v} \beta 3$ integrin, a well-characterized cell adhesion molecule on the luminal surface of the endometrium. Importance of the expression of the $\beta 3$ integrin subunit gene has been demonstrated by observations in women that aberrant expression of integrins in the endometrium often results in endometriosis, which is associated with infertility due to defective uterine receptivity and implantation failure [62]. From these observations, one possible mechanism in the regulation of implantation is proposed: changes in $\mathrm{E}_{2}$ and $\mathrm{P}_{4}$ during the estrous cycle induce Hoxa-10 in the endometrium, which up-regulates the expression of integrins on the endometrial surface, resulting in the attachment of conceptus and uterine endometrium. The product of the homeobox gene Hoxa-11, localized next to the Hoxa-10 gene on chromosome 6 , has been shown to possess a function similar to Hoxa-10. In fact, Hoxa-11 mutant female mice are sterile due to their defective uterine environments, since normal litters are obtained when blastocysts from homozygous mutant females are transferred to wild-type mothers [63].

\section{Cytokines}

Many cytokines are expressed in the uterus, but only a few have been shown to be required for trophoblast implantation. The clearest example is 
the requirement for implantation of maternally produced leukemia inhibitory factor (LIF). In the mouse, LIF has been shown to be expressed in the endometrial glands at the time of blastocyst implantation and is secreted into the uterine lumen [64]. In other mammalian species, including human and ruminants, LIF expression in the uterus is also up-regulated around the onset of blastocyst implantation, suggesting that LIF may be of general significance to blastocyst implantation in mammals [65]. Homozygous LIF mutant mouse blastocysts survive to adulthood, but females are sterile. Null mutant blastocysts, when transferred to the uterus of wild type mice, will implant and develop normally, but the wild type blastocysts do not implant in the uteri of mice with the null mutation in the LIF gene [66]. Thus, endometrial LIF appears to play an essential role in the process of implantation as a factor possibly regulating uterine receptivity. The next question is what regulates LIF expression in the endometrium. Analysis using LIF deficient mice shows that up to the onset of implantation, changes in uterine cell proliferation, hormone levels, blastocyst localization, as well as expression of lactoferrin and Muc-1, do not differ from those in wild-type mice. However, the uterus of the null mutant mouse fails to undergo decidual response to the presence of blastocysts or to artificial stimuli [67]. In rodents, implantation is stimulated by a transient rise in circulating $E_{2}$ levels, the nidatory surge, on 4.5 d.p.c. $[68,69]$. Nidatory $E_{2}$ required for implantation and decidualization in ovariectomized mice could be replaced with uterine expression of LIF [67]. There is still insufficient information on how LIF, upregulated by $\mathrm{E}_{2}$ and secreted into uterine lumen, works on the uterus and modulates uterine receptivity and blastocyst implantation. It has so far been shown that LIF acts through the LIF receptor located in the uterine luminal epithelial cells, which activates signal transducer and activator of transcription (Stat) 3 [70]. Thus, one possible mechanism by which $\mathrm{E}_{2}$ modulates uterine receptivity and implantation is through its upregulation of endometrial LIF expression and subsequent activation of Stat3. It is thought that LIF is required not only for uterine receptivity, but also for the maintenance of the ICM's pluripotency. LIF was found to inhibit differentiation of mouse ES cells [71, 72]. In addition, ICM from which LIF is removed rapidly loses self-renewal capacity and the ability to differentiate into a variety of cell types. As both LIF and Oct-4 contribute to the maintenance of the ICM's pluripotency, the potential relationship between these two molecules must be evaluated. Though few experiments have reached definitive conclusions, it appears that effects of LIF and Oct- 4 on the retention of cellular pluripotency are exerted in independent pathways [73], and both LIF and Oct- 4 are necessary for the maintenance of ICM. Thus, LIF exerts another function as a possible regulator of many important molecules involved in the first cell differentiation of ICM and trophectoderm lineages. These multiple functions of LIF also provide the possible evidence for its role as a maternal-conceptus communication tool: maternally expressed LIF acts on the fertilized ovum and induces its differentiation to form the blastocyst.

Detection of high concentrations of a cytokine, macrophage-colony stimulating factor (M-CSF or CSF-1) in the mouse uterus during pregnancy suggests that M-CSF plays a role outside the hematopoietic system [74]. The synthesis of M-CSF by the uterus, at least during the early part of pregnancy, is regulated by $\mathrm{E}_{2}$ and $\mathrm{P}_{4}[75,76]$. Results from M-CSF null mutant mice suggest that M-CSF is required for pregnancy, however, the only defect in M-CSF null mice appears to only be smaller litter sizes, indicating that maternal M-CSF may not be an absolute requirement for embryonic survival and development [77].

Interleukin-1 (IL-1) has also been implicated in the process of implantation, since IL-1 mRNA, localized in the peri-implantation mouse uterus, increases from 3.5 d.p.c. and peaks between 4.5 and 5.5 d.p.c. with blastocyst implantation occurring late on 4.5 d.p.c. [78]. IL-1 receptor is also found in the mouse uterus around the time of implantation $[79,80]$. In humans, IL-1 and its receptor are detected in the endometrium during the implantation process $[81,82]$. Injection of IL-1 receptor antagonist into mice to block the receptor results in blocking of blastocyst attachment to the uterus [83], indicating an important role for IL-1 during the implantation period. However, in the IL-1 $\beta$ gene knockout mouse, reproduction is near normal [84], and mice with the IL-1 receptor deletion are also fertile with a slight reduction in mean litter size [85]. Thus, single deletion of IL-1 or its receptor does not result in implantation defects. Indirect mechanisms by which IL-1 affects 
implantation have been evaluated. IL-1 is a potent inducer of LIF expression in cultured human endometrial stromal cells [86]. IL-1 also stimulates prostaglandins (PGs) production by activating cyclooxygenase (COX)-2 expression [87]. PGs have long been speculated to be involved in many aspects of the reproductive functions including implantation and decidualization. COX is an enzyme involved in PG biosynthesis and exists in two isoforms, COX-1 and COX-2. Both COX-1 and COX-2 genes are expressed in the 4.5 d.p.c. mouse uterus, supporting the important roles of COX genes and PGs during the implantation periods [88]. However, COX-1 homozygous mutant females are fertile with limited parturition defects [89], whereas COX-2 deficient female mice are infertile [90]. The COX-2 null mouse shows multiple failures in female reproductive processes including ovulation, fertilization, implantation and decidualization. Further, the implantation defect seen in COX-2 null mice has been demonstrated to be due to a lack of proper production of PGs [91]. Thus, COX-2 expression in the uterus, which is partly stimulated by IL-1, causes increases in PG production that are required for successful implantation. In the uterus, therefore, cytokines appear to interact with each other to regulate various aspects of the implantation process.

\section{Communication between Conceptus and Maternal Uterine Endometrium before Implantation}

It is known that the uterus and conceptus initiate and maintain biochemical communications during the pre-implantation period. Numerous observations have revealed that the uterus in the state of "implantation window" allows the conceptus to attach and then invade toward the properly conditioned endometrium, resulting from maternal-conceptus cross talk during the preimplantation period. In the mouse, LIF receptor or M-CSF receptor is expressed by the conceptuses during the pre-implantation period [92, 93], indicating that LIF or M-CSF is a possible communicator functioning in the maternalconceptus communication. However, molecular mechanisms by which implantation is established have not been definitively established. This could be due to the fact that the pre-implantation period is very short and a proper in vitro model has not been established. From animal species that have conceptus elongations, maternal-conceptus communication may become more important than in the species such as rodents and primates where the implantation process starts immediately after hatching. The long pre-attachment period during which ruminants' trophoblasts proliferate and elongate extensively has made the maternalconceptus communication mechanisms more apparent.

In ruminant ungulates such as sheep, cow and goat, a conceptus cytokine, interferon-tau (IFN- $\tau$ ), is known as a key factor that elicits the process of maternal recognition of pregnancy [94-96]. The expression of IFN- $\tau$ is limited to the embryonic trophectoderm during the peri-implantation period [97-100]. The ovine blastocyst begins to secrete IFN- $\tau$ immediately after hatching. Its secretion increases markedly when the blastocyst starts to elongate [101] and reaches the maximum level when conceptus attachment to the uterus is initiated on day $16[97,102]$. The secretion of IFN- $\tau$ decreases rapidly as the process of implantation proceeds and when the conceptus is fully attached to the endometrium, IFN- $\tau$ is no longer detected [97]. These temporal and spatial expression patterns indicate the existence of an early, trophoblast specific, regulatory mechanism for IFN- $\tau$ gene expression.

In mammals, $\mathrm{P}_{4}$ secreted from the corpus luteum $(\mathrm{CL})$ is necessary to maintain pregnancy. When ruminants do not become pregnant, prostaglandin $\mathrm{F}_{2 \alpha}\left(\mathrm{PGF}_{2 \alpha}\right)$ derived from the endometrium induces CL regression and the estrous cycle resumes [103, 104]. Conceptus IFN- $\tau$ binds to a type I IFN receptor (IFNAR) located on luminal epithelial cells of the endometrium [105-107], and reduces the numbers of ER and oxytocin receptor (OXY-R) [108-110]. This binding eventually results in the attenuation of endometrial $\mathrm{PGF}_{2 \alpha}$ secretion, which leads to CL maintenance and continued production of $\mathrm{P}_{4}$.

While IFN- $\tau$ secreted from the conceptus affects the uterine endometrium in a paracrine manner, maternal factors are thought to be essential for the activation of IFN- $\tau$ expression. In bovine species, in vitro fertilized and cultured blastocysts start to produce IFN $-\tau$ without maternal uterine influences. However, if these blastocysts are transferred to the uterus and are again cultured after the recovery, 


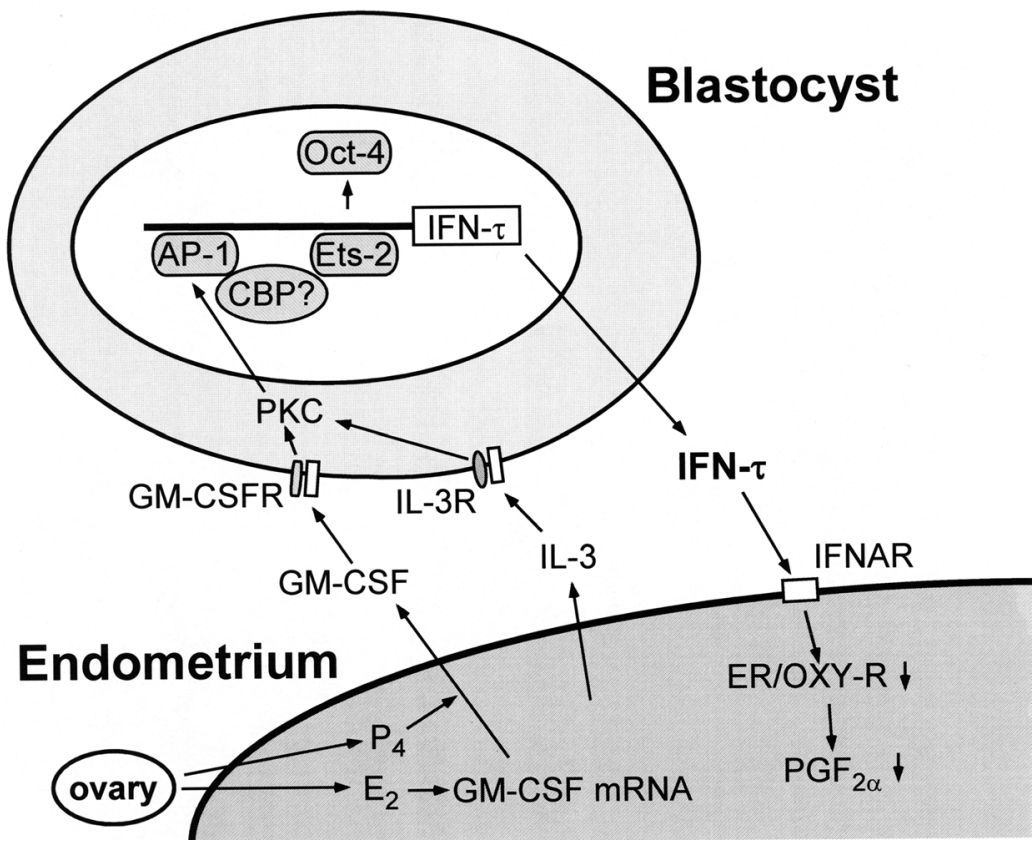

Fig. 2. IFN- $\tau$ production resulting from maternal-conceptus communications during early conceptus development in ruminant ungulates. Uterine endometrium derived cytokines, IL-3 and GM-CSF. mRNAs and proteins, are up-regulated by $\mathrm{E}_{2}$ and $\mathrm{P}_{4}$, respectively. In the conceptus these cytokines increase expression of IFN- $\tau$ through their respective receptors and by intra-cellular signaling through the protein kinase $C$ system (PKC). Transcription factor AP-1 activated by PKC is an important factor that enhances IFN- $\tau$ transcription. Another transcription factor Ets- 2 is not an effective transcription activator when bound to Oct- 4 . Once Oct- 4 expression subsides or is dissociated from Ets-2, Ets-2 becomes available for IFN- $\tau$ gene expression when co-activator CBP connects AP-1 and Ets2. During the pre-attachment period, conceptus IFN- $\tau$ attaches to its endometrial receptor, IFNAR, in a paracrine manner, which reduces the number of estrogen receptor (ER) and possibly oxytocin receptor (OXY$\mathrm{R})$, resulting in the attenuation of a uterine luteolysin, $\mathrm{PGF}_{2 \alpha}$. This pathway results in corpus luteum maintenance and assures the continued production of $\mathrm{P}_{4}$ by the ovary.

they produce approximately 1,000 times more IFN$\tau$ [111], suggesting that IFN- $\tau$ production in vivo is supported by endometrial factors. Imakawa et al. demonstrated that the IFN- $\tau$ gene is up-regulated by cytokines, granulocyte macrophage-colony stimulating factor (GM-CSF) and IL-3, which are produced by the ovine endometrium and are readily available to the conceptus [112, 113]. Ovarian steroid hormones appear to regulate endometrial expression of GM-CSF: Endometrial GM-CSF mRNA is up-regulated by $\mathrm{E}_{2}$ and its protein production increases with $\mathrm{P}_{4}$ treatment [114]. To elucidate how GM-CSF or IL-3 enhances IFN- $\tau$ expression, identification of intra-cellular signaling and/or transcription factors that could regulate IFN- $\tau$ expression was required. Several transcription factors, which appear to regulate IFN$\tau$ gene expression, have so far been identified from in vitro studies. Transcription factor activated protein 1 (AP-1), a target of an intra-cellular signaling, protein kinase $\mathrm{C}$ (PKC), has been shown to enhance IFN $\tau$ expression, resulting from PKC activation by maternal GM-CSF $[115,116]$. Ets-2, which often works in collaboration with other transcription factors like AP-1, has also been demonstrated to be an activator of IFN $-\tau$ [117]. Considering this with the defective trophoblast function in Ets-2 null mice [10], Ets-2 appears to 
play an important role in the trophoblast of many species during the peri-implantation period. Recently, a transcriptional co-activator CREBbinding protein (CBP), has been shown to activate IFN- $\tau$ transcription [118]. Because CBP has both AP-1 and Ets-2 binding domains, CBP could be a factor that incorporates effects of AP-1 and Ets-2 on the potentiation of IFN- $\tau$ gene transcription. As previously mentioned, mouse embryonic Oct-4, which is expressed only in ICM and not in the trophoblast, is required for ICM differentiation and subsequent ICM development. Oct-4 has recently been suggested to be the repressor for IFN- $\tau$ gene regulation since Oct-4 represses IFN- $\tau$ transactivation through its binding to Ets-2 in the IFN- $\tau$ upstream region [119], fairly consistent with the time- and cell-specific expression of IFN $-\tau$ by trophoblast cells.

From these observations, it appears that IFN- $\tau$ expression is activated by both AP-1 and Ets-2, however, its expression is usually kept suppressed because experiments on the regulation of IFN- $\tau$ expression indicate that the decrease in Oct-4 expression in trophoblast cells removes its suppressive action on IFN- $\tau$ gene transcription [119]. Results from ruminant and rodent experimentation suggest that Oct-4 may be repressing many important genes, which are involved in trophoblast differentiation and functions. At the same time, Oct-4, which is known to have both gene activating and gene repressing functions, activates genes such as FGF-4 that is required for ICM maintenance [32, 33]. These gene expressions regulated by Oct- 4 may result in differentiation of ICM and trophoblast cell lineages in blastocysts, which lead to the expression of critical factors like IFN- $\tau$ that is essential for the implantation process.

Accumulated evidence suggests that IFN- $\tau$ is regulated by maternal factors, however, the degree to which the conceptus itself contributes to IFN- $\tau$ expression has not been well-characterized. In addition to the activation by transcription factors like AP-1 and Ets-2 [96, 116], conceptus elongation resulting from rapid trophoblast cell proliferation should greatly contribute to IFN- $\tau$ secretion. These transcription factors increase IFN $-\tau$ production by enhancing the IFN $-\tau$ gene transcription of each cell, but the trophoblast elongation also increases IFN- $\tau$ secretion due to the proliferation of the number of IFN- $\tau$ producing cells. Since DNA replication and cell division are repeated in the cell proliferation process, cell cycle related molecules might also be involved in ruminant trophoblast proliferation leading to IFN $-\tau$ activation. Although there is no direct evidence, this hypothesis is supported by experiments with mice in which cell cycle related molecules like CDC45 affect implantation.

Although several factors that regulate IFN- $\tau$ production have been detected [96], how IFN- $\tau$ exhibits such a specific, temporal and spatial, expression has not been elucidated. Discovery of more factors and their interactions may resolve molecular mechanisms regulating IFN- $\tau$ gene expression. Results obtained from such experimentation may then reveal fundamental mechanisms of maternal-conceptus communications beyond the ruminant ungulates, which determine the success or failure of many implantation processes.

\section{Concluding Remarks}

To date there have been many reports dealing with biochemical and molecular mechanisms of implantation, but understanding of the regulation of implantation processes is far from being resolved. As discussed in this review, whether or not the blastocysts go through successful implantation may have already begun long before the conceptus attachment to the endometrium. Both pre-implantation conceptus development and uterine preparation including the cross talk of maternal and conceptus tissues should be examined further to fully understand the mechanisms of implantation. The observations that ruminants have a long pre-attachment period and a typical maternal-conceptus cross talk molecule like IFN- $\tau$ leads to the hypothesis that ruminants require longer and closer communications between the uterus and conceptus than those of rodents and primates. This characteristic of the implantation process in ruminants should make it possible to understand the mechanisms of maternal-conceptus cross talk that has been difficult to analyze in species like rodents whose pre-implantation period is very short. The processes of implantation represent both unique and common aspects among the species. Mammalian implantation analyses will advance when differences in the characteristics of each species are integrated into such experiments. 
In addition, a wider range of molecules, including DNA replication factor CDC45, should be studied further if such factors have roles in the implantation process. These approaches that focus on new aspects of implantation will reveal the associations of all implantation-related factors, which could solve the problems associated with implantation rates in humans and domestic animals.

\section{Acknowledgements}

The authors would like to thank Ms. Fuko Matsuda, a former student, for her contribution to the initial version of this review article. This work was supported by a Grant-in-Aid for Scientific Research (14206032) to KI from the Japan Society for the Promotion of Science.

\section{References}

1. Rogers MB, Hosler BA, Gudas LJ. Specific expression of a retinoic acid-regulated, zinc-finger gene, Rex-1, in preimplantation embryos, trophoblast and spermatocytes. Development 1991; 113: 815-824.

2. Ng YK, George KM, Engel JD, Linzer DI. GATA factor activity is required for the trophoblastspecific transcriptional regulation of the mouse placental lactogen I gene. Development 1994; 120: 3257-3266.

3. Ciruna BG, Rossant J. Expression of the T-box gene Eomesodermin during early mouse development. Mech Dev 1999; 81: 199-203.

4. Hancock SN, Agulnik SI, Silver LM, Papaioannou VE. Mapping and expression analysis of the mouse ortholog of Xenopus Eomesodermin. Mech Dev 1999; 81: 205-208.

5. Beck F, Erler T, Russell A, James R. Expression of $\mathrm{Cdx}-2$ in the mouse embryo and placenta: possible role in patterning of the extra-embryonic membranes. Dev Dyn 1995; 204: 219-227.

6. Shi D, Kellems RE. Transcription factor AP-2 gamma regulates murine adenosine deaminase gene expression during placental development. J Biol Chem 1998; 273: 27331-27338.

7. Sapin V, Bouillet $\mathbf{P}$, Oulad-Abdelghani $\mathbf{M}$, Dastugue B, Chambon P, Dolle P. Differential expression of retinoic acid-inducible (Stra) genes during mouse placentation. Mech Dev 2000; 92: 295299.

8. Rossant J, Guillemot F, Tanaka M, Latham K, Gertenstein M, Nagy A. Mash2 is expressed in oogenesis and preimplantation development but is not required for blastocyst formation. Mech Dev 1998; 73: 183-191.

9. Cross JC, Flannery ML, Blanar MA, Steingrimsson E, Jenkins NA, Copeland NG, Rutter WJ, Werb Z. Hxt encodes a basic helix-loop-helix transcription factor that regulates trophoblast cell development. Development 1995; 121: 2513-2523.

10. Yamamoto $\mathbf{H}$, Flannery ML, Kupriyanov S, Pearce J, McKercher SR, Henkel GW, Maki RA, Werb Z,
Oshima RG. Defective trophoblast function in mice with a targeted mutation of Ets2. Genes Dev 1998; 12: 1315-1326.

11. Chawengsaksophak $\mathbf{K}$, James $\mathbf{R}$, Hammond VE, Kontgen F, Beck F. Homeosis and intestinal tumours in Cdx2 mutant mice. Nature 1997; 386: 8487.

12. Russ AP, Wattler S, Colledge WH, Aparicio SA, Carlton MB, Pearce JJ, Barton SC, Surani MA, Ryan K, Nehls MC, Wilson V, Evans MJ. Eomesodermin is required for mouse trophoblast development and mesoderm formation. Nature 2000; 404: 95-99.

13. Guillemot F, Nagy A, Auerbach A, Rossant J, Joyner AL. Essential role of Mash-2 in extraembryonic development. Nature 1994; 371: 333336.

14. Riley P, Anson-Cartwright L, Cross JC. The Hand1 bHLH transcription factor is essential for placentation and cardiac morphogenesis. Nat Genet 1998; 18: 271-275.

15. Scott IC, Anson-Cartwright L, Riley P, Reda D, Cross JC. The HAND1 basic helix-loop-helix transcription factor regulates trophoblast differentiation via multiple mechanisms. Mol Cell Biol 2000; 20: 530-541.

16. Ryan K, Garrett N, Mitchell A, Gurdon JB. Eomesodermin, a key early gene in Xenopus mesoderm differentiation. Cell 1996; 87: 989-1000.

17. James R, Kazenwadel J. Homeobox gene expression in the intestinal epithelium of adult mice. J Biol Chem 1991; 266: 3246-3251.

18. Shi D, Winston JH, Blackburn MR, Datta SK, Hanten G, Kellems RE. Diverse genetic regulatory motifs required for murine adenosine deaminase gene expression in the placenta. J Biol Chem 1997; 272: 2334-2341.

19. Richardson BD, Langland RA, Bachurski CJ, Richards RG, Kessler CA, Cheng YH, Handwerger S. Activator protein-2 regulates human placental lactogen gene expression. Mol Cell Endocrinol 2000; 160: 183-192. 
20. Johnson W, Jameson JL. AP-2 (activating protein 2) and Sp1 (selective promoter factor 1) regulatory elements play distinct roles in the control of basal activity and cyclic adenosine 3',5'-monophosphate responsiveness of the human chorionic gonadotropin-beta promoter. Mol Endocrinol 1999; 13: 1963-1975.

21. Auman HJ, Nottoli T, Lakiza O, Winger $Q$, Donaldson S, Williams T. Transcription factor AP$2 \gamma$ is essential in the extra-embryonic lineages for early postimplantation development. Development 2002; 129: 2733-2747.

22. Werling U, Schorle H. Transcription factor gene AP-2 gamma essential for early murine development. Mol Cell Biol 2002; 22: 3149-3156.

23. Radice G, Lee JJ, Costantini F. H $\beta 58$, an insertional mutation affecting early postimplantation development of the mouse embryo. Development 1991; 111: 801-811.

24. Lee JJ, Radice G, Perkins CP, Costantini F. Identification and characterization of a novel, evolutionarily conserved gene disrupted by the murine $\mathrm{H} \beta 58$ embryonic lethal transgene insertion. Development 1992; 115: 277-288.

25. Maroulakou IG, Papas TS, Green JE. Differential expression of ets-1 and ets-2 proto-oncogenes during murine embryogenesis. Oncogene 1994; 9: 1551-1565.

26. Scholer HR, Dressler GR, Balling R, Rohdewohld $H$, Gruss P. Oct-4: a germline-specific transcription factor mapping to the mouse t-complex. EMBO J 1990; 9: 2185-2195.

27. Palmieri SL, Peter W, Hess H, Scholer HR. Oct-4 transcription factor is differentially expressed in the mouse embryo during establishment of the first two extraembryonic cell lineages involved in implantation. Dev Biol 1994; 166: 259-267.

28. Nichols J, Zevnik B, Anastassiadis K, Niwa H, Klewe-Nebenius D, Chambers I, Scholer H, Smith A. Formation of pluripotent stem cells in the mammalian embryo depends on the POU transcription factor Oct-4. Cell 1998; 95: 379-391.

29. Niswander L, Martin GR. Fgf-4 expression during gastrulation, myogenesis, limb and tooth development in the mouse. Development 1992; 114: 755-768.

30. Rappolee DA, Basilico C, Patel Y, Werb Z. Expression and function of FGF-4 in periimplantation development in mouse embryos. Development 1994; 120: 2259-2269.

31. Feldman B, Poueymirou W, Papaioannou VE, DeChiara TM, Goldfarb M. Requirement of FGF-4 for postimplantation mouse development. Science 1995; 267: 246-249.

32. Yuan H, Corbi N, Basilico C, Dailey L. Developmental-specific activity of the FGF-4 enhancer requires the synergistic action of Sox 2 and
Oct-3. Genes Dev 1995; 9: 2635-2645.

33. Ambrosetti DC, Scholer HR, Dailey L, Basilico C. Modulation of the activity of multiple transcriptional activation domains by the DNA binding domains mediates the synergistic action of Sox 2 and Oct-3 on the fibroblast growth factor-4 enhancer. J Biol Chem 2000; 275: 23387-23397.

34. Orr-Urtreger A, Bedford MT, Burakova T, Arman E, Zimmer Y, Yayon A, Givol D, Lonai P. Developmental localization of the splicing alternatives of fibroblast growth factor receptor-2 (FGFR2). Dev Biol 1993; 158: 475-486.

35. Rappolee DA, Patel Y, Jacobson K. Expression of fibroblast growth factor receptors in periimplantation mouse embryos. Mol Reprod Dev 1998; 51: 254-264.

36. Haffner-Krausz R, Gorivodsky M, Chen Y, Lonai P. Expression of Fgfr2 in the early mouse embryo indicates its involvement in preimplantation development. Mech Dev 1999; 85: 167-172.

37. Chai N, Patel Y, Jacobson K, McMahon J, McMahon A, Rappolee DA. FGF is an essential regulator of the fifth cell division in preimplantation mouse embryos. Dev Biol 1998; 198: 105-115.

38. Arman E, Haffner-Krausz R, Chen Y, Heath JK, Lonai P. Targeted disruption of fibroblast growth factor (FGF) receptor 2 suggests a role for FGF signaling in pregastrulation mammalian development. Proc Natl Acad Sci USA 1998; 95: 50825087.

39. Tanaka S, Kunath T, Hadjantonakis AK, Nagy A, Rossant J. Promotion of trophoblast stem cell proliferation by FGF4. Science 1998; 282: 2072-2075.

40. Yoshida K, Kuo F, George EL, Sharpe AH, Dutta A. Requirement of CDC45 for postimplantation mouse development. Mol Cell Biol 2001; 21: 4598-4603.

41. Hopwood B, Dalton S. Cdc45p assembles into a complex with Cdc46p/Mcm5p, is required for minichromosome maintenance, and is essential for chromosomal DNA replication. Proc Natl Acad Sci USA 1996; 93: 12309-12314.

42. Owens JC, Detweiler CS, Li JJ. CDC45 is required in conjunction with $\mathrm{CDC7/DBF} 4$ to trigger the initiation of DNA replication. Proc Natl Acad Sci USA 1997; 94: 12521-12526.

43. Zou L, Mitchell J, Stillman B. CDC45, a novel yeast gene that functions with the origin recognition complex and Mcm proteins in initiation of DNA replication. Mol Cell Biol 1997; 17: 553-563.

44. Saha $\mathbf{P}$, Thome KC, Yamaguchi R, Hou Z, Weremowicz S, Dutta A. The human homolog of Saccharomyces cerevisiae CDC45. J Biol Chem 1998; 273: 18205-18209.

45. Kukimoto I, Igaki H, Kanda T. Human CDC45 protein binds to minichromosome maintenance 7 protein and the p70 subunit of DNA polymerase alpha. Eur J Biochem 1999; 265: 936-943. 
46. Bultman S, Gebuhr T, Yee D, La Mantia C, Nicholson J, Gilliam A, Randazzo F, Metzger D, Chambon P, Crabtree G, Magnuson T. A Brg1 null mutation in the mouse reveals functional differences among mammalian SWI/SNF complexes. Mol Cell 2000; 6: 1287-1295.

47. Liu Q, Guntuku S, Cui XS, Matsuoka S, Cortez D, Tamai K, Luo G, Carattini-Rivera S, DeMayo F, Bradley A, Donehower LA, Elledge SJ. Chk1 is an essential kinase that is regulated by Atr and required for the G(2)/M DNA damage checkpoint. Genes Dev 2000; 14: 1448-1459.

48. Tateishi K, Omata M, Tanaka K, Chiba T. The NEDD8 system is essential for cell cycle progression and morphogenetic pathway in mice. J Cell Biol 2001; 155: 571-579.

49. Rossi DJ, Londesborough A, Korsisaari N, Pihlak A, Lehtonen E, Henkemeyer M, Makela TP. Inability to enter $S$ phase and defective RNA polymerase II CTD phosphorylation in mice lacking Mat1. EMBO J 2001; 20: 2844-2856.

50. Yoshinaga K, Adams CE. Delayed implantation in the spayed, progesterone treated adult mouse. $J$ Reprod Fertil 1966; 12: 593-595.

51. Lubahn DB, Moyer JS, Golding TS, Couse JF, Korach KS, Smithies O. Alteration of reproductive function but not prenatal sexual development after insertional disruption of the mouse estrogen receptor gene. Proc Natl Acad Sci USA 1993; 90: 11162-11166.

52. Lydon JP, DeMayo FJ, Funk CR, Mani SK, Hughes AR, Montgomery CA Jr, Shyamala G, Conneely OM, O'Malley BW. Mice lacking progesterone receptor exhibit pleiotropic reproductive abnormalities. Genes Dev 1995; 9: 2266-2278.

53. Satokata I, Benson G, Maas R. Sexually dimorphic sterility phenotypes in Hoxa10-deficient mice. Nature 1995; 374: 460-463.

54. Benson GV, Lim H, Paria BC, Satokata I, Dey SK, Maas RL. Mechanisms of reduced fertility in Hoxa10 mutant mice: uterine homeosis and loss of maternal Hoxa-10 expression. Development 1996; 122: 2687-2696.

55. Ma L, Benson GV, Lim H, Dey SK, Maas RL. Abdominal B (AbdB) Hoxa genes: regulation in adult uterus by estrogen and progesterone and repression in mullerian duct by the synthetic estrogen diethylstilbestrol (DES). Dev Biol 1998; 197: 141-154.

56. Taylor HS, Arici A, Olive D, Igarashi P. HOXA10 is expressed in response to sex steroids at the time of implantation in the human endometrium. J Clin Invest 1998; 101: 1379-1384.

57. Taylor HS, Vanden Heuvel GB, Igarashi P. A conserved Hox axis in the mouse and human female reproductive system: late establishment and persistent adult expression of the Hoxa cluster genes. Biol Reprod 1997; 57: 1338-1345.

58. Daftary GS, Troy PJ, Bagot CN, Young SL, Taylor HS. Direct regulation of $\beta 3$-integrin subunit gene expression by HOXA10 in endometrial cells. Mol Endocrinol 2002; 16: 571-579.

59. Hynes R. Integrins: a family of cell surface receptors. Cell 1987; 48: 549-554.

60. Gumbiner BM. Cell adhesion: the molecular basis of tissue architecture and morphogenesis. Cell 1996; 84: 345-357.

61. Lessey BA. Endometrial integrins and the establishment of uterine receptivity. Hum Reprod 1998; 3: 247-261.

62. Lessey BA, Castelbaum AJ, Sawin SW, Buck CA, Schinnar R, Bilker W, Strom BL. Aberrant integrin expression in the endometrium of women with endometriosis. J Clin Endocrinol Metab 1994; 79: 643649.

63. Hsieh-Li HM, Witte DP, Weinstein M, Branford W, Li H, Small K, Potter SS. Hoxa 11 structure, extensive antisense transcription, and function in male and female fertility. Development 1995; 121: 1373-1385.

64. Bhatt H, Brunet LJ, Stewart CL. Uterine expression of leukemia inhibitory factor coincides with the onset of blastocyst implantation. Proc Natl Acad Sci USA 1991; 88: 11408-11412.

65. Vogiagis D, Salamonsen LA. The role of leukaemia inhibitory factor in the establishment of pregnancy. J Endocrinol 1999; 160: 181-190.

66. Stewart CL, Kaspar P, Brunet LJ, Bhatt H, Gadi I, Kontgen F, Abbondanzo SJ. Blastocyst implantation depends on maternal expression of leukaemia inhibitory factor. Nature 1992; 359: 76-79.

67. Chen JR, Cheng JG, Shatzer T, Sewell L, Hernandez L, Stewart CL. Leukemia inhibitory factor can substitute for nidatory estrogen and is essential to inducing a receptive uterus for implantation but is not essential for subsequent embryogenesis. Endocrinology 2000; 141: 4365-4372.

68. Finn CA, Martin L. The control of implantation. J Reprod Fertil 1974; 39: 195-206.

69. McCormack JT, Greenwald GS. Evidence for a preimplantation rise in oestradiol-17 $\beta$ levels on day 4 of pregnancy in the mouse. J Reprod Fertil 1974; 41: 297-301.

70. Cheng JG, Chen JR, Hernandez L, Alvord WG, Stewart CL. Dual control of LIF expression and LIF receptor function regulate Stat3 activation at the onset of uterine receptivity and embryo implantation. Proc Natl Acad Sci USA 2001; 98: 86808685.

71. Smith AG, Heath JK, Donaldson DD, Wong GG, Moreau J, Stahl M, Rogers D. Inhibition of pluripotential embryonic stem cell differentiation by purified polypeptides. Nature 1988; 336: 688-690.

72. Williams RL, Hilton DJ, Pease S, Willson TA, 
Stewart CL, Gearing DP, Wagner EF, Metcalf D, Nicola NA, Gough NM. Myeloid leukaemia inhibitory factor maintains the developmental potential of embryonic stem cells. Nature 1988; 336: 684-687.

73. Niwa H, Miyazaki J, Smith AG. Quantitative expression of Oct-3/4 defines differentiation, dedifferentiation or self-renewal of ES cells. Nat Genet 2000; 24: 372-376.

74. Bartocci A, Pollard JW, Stanley ER. Regulation of colony-stimulating factor 1 during pregnancy. J Exp Med 1986; 164: 956-961.

75. Pollard JW, Bartocci A, Arceci R, Orlofsky A, Ladner MB, Stanley ER. Apparent role of the macrophage growth factor, CSF-1, in placental development. Nature 1987; 330: 484-486.

76. Arceci RJ, Shanahan F, Stanley ER, Pollard JW. Temporal expression and location of colonystimulating factor 1 (CSF-1) and its receptor in the female reproductive tract are consistent with CSF-1regulated placental development. Proc Natl Acad Sci USA 1989; 86: 8818-8822.

77. Pollard JW, Hunt JS, Wiktor-Jedrzejczak W, Stanley ER. A pregnancy defect in the osteopetrotic (op/op) mouse demonstrates the requirement for CSF-1 in female fertility. Dev Biol 1991; 148: 273-283.

78. De M, Sanford TR, Wood GW. Expression of interleukin 1, interleukin 6 and tumour necrosis factor $\alpha$ in mouse uterus during the periimplantation period of pregnancy. I Reprod Fertil 1993; 97: 83-89.

79. Simon C, Piquette GN, Frances A, Westphal LM, Heinrichs WL, Polan ML. Interleukin-1 type I receptor messenger ribonucleic acid expression in human endometrium throughout the menstrual cycle. Fertil Steril 1993; 59: 791-796.

80. Simon C, Piquette GN, Frances A, Polan ML. Localization of interleukin-1 type I receptor and interleukin-1 beta in human endometrium throughout the menstrual cycle. J Clin Endocrinol Metab 1993; 77: 549-555.

81. Kauma S, Matt D, Strom S, Eierman D, Turner T. Interleukin-1 $\beta$ (IL-1 $\beta$ ), human leukocyte antigen HLA-DR $\alpha$, and transforming growth factor- $\beta$ (TGF$\beta)$ expression in endometrium, placenta and placental membranes. Am J Obstet 1990; 163: 14301437.

82. Takacs $\mathbf{P}$, Kauma $\mathbf{S}$. The expression of interleukin-1 alpha, interleukin-1 beta, and interleukin-1 receptor type I mRNA during preimplantation mouse development. J Reprod Immunol 1996; 32: 27-35.

83. Simon C, Frances A, Piquette GN, Danasouri IE, Zurawski G, Dang W, Polan ML. Embryonic implantation in mice is blocked by interleukin-1 receptor antagonist. Endocrinology 1994; 134: 521528.

84. Zheng H, Fletcher D, Kozak W, Jiang M, Hofmann
KJ, Conn CA, Soszynski D, Grabiec C, Trumbauer ME, Shaw A, Kostura MJ, Stevens K, Rosen H, North RJ, Chen HY, Tocci MJ, Kluger MJ, Ploeg LH. Resistance to fever induction and impaired acute-phase response in interleukin-1 beta-deficient mice. Immunity 1995; 3: 9-19.

85. Abbondanzo SJ, Cullinan EB, McIntyre K, Labow MA, Stewart CL. Reproduction in mice lacking a functional type IL-1 receptor. Endocrinology 1996; 137: 3598-3601.

86. Arici A, Engin O, Attar E, Olive DL. Modulation of leukemia inhibitory factor gene expression and protein biosynthesis in human endometrium. J Clin Endocrinol Metab 1995; 80: 1908-1915.

87. Huang JC, Liu DY, Yadollahi S, Wu KK, Dawood MY. Interleukin- $1 \beta$ induces cyclooxygenase- 2 gene expression in cultured endometrial stromal cells. $J$ Clin Endocrinol Metab 1998; 83: 538-541.

88. Chakraborty I, Das SK, Wang J, Dey SK. Developmental expression of the cyclo-oxygenase-1 and cyclo-oxygenase- 2 genes in the periimplantation mouse uterus and their differential regulation by the blastocyst and ovarian steroids. $J$ Mol Endocrinol 1996; 16: 107-122.

89. Langenbach R, Morham SG, Tiano HF, Loftin CD, Ghanayem BI, Chulada PC, Mahler JF, Lee CA, Goulding EH, Kluckman KD. Prostaglandin synthase 1 gene disruption in mice reduces arachidonic acid-induced inflammation and indomethacin-induced gastric ulceration. Cell 1995; 83: 483-492.

90. Dinchuk JE, Car BD, Focht RJ, Johnston JJ, Jaffee BD, Covington MB, Contel NR, Eng VM, Collins RJ, Czerniak PM, Gorry SA, Trzaskos JM. Renal abnormalities and an altered inflammatory response in mice lacking cyclooxygenase II. Nature 1995; 378: 406-409.

91. Lim H, Paria BC, Das SK, Dinchuk JE, Langenbach R, Trzaskos JM, Dey SK. Multiple female reproductive failures in cyclooxygenase 2-deficient mice. Cell 1997; 91: 197-208.

92. Arceci RJ, Pampfer S, Pollard JW. Expression of CSF-1/c-fms and SF/c-kit mRNA during preimplantation mouse development. Dev Biol 1992; 151: 1-8.

93. Chen HF, Shew JY, Ho HN, Hsu WL, Yang YS. Expression of leukemia inhibitory factor and its receptor in preimplantation embryos. Fertil Steril 1999; 72: 713-719.

94. Imakawa K, Anthony RV, Kazemi M, Marotti KR, Polites, Roberts RM. Interferon-like sequence of ovine trophoblast protein secreted by embryonic trophectoderm. Nature 1987; 330: 377-379.

95. Roberts RM, Cross JC, Leaman DW. Interferons as hormones of pregnancy. Endocr Rev 1992; 13: 432452.

96. Demmers KJ, Derecka K, Flint A. Trophoblast 
interferon and pregnancy. Reproduction 2001; 121: 41-49.

97. Godkin JD, Bazer FW, Moffatt J, Sessions F, Roberts RM. Purification and properties of a major, low molecular weight protein released by the trophoblast of sheep blastocysts at day 13-21. J Reprod Fertil 1982; 65: 141-150.

98. Hansen TR, Imakawa K, Polites HG, Marotti KR, Anthony RV, Roberts RM. Interferon RNA of embryonic origin is expressed transiently during early pregnancy in the ewe. J Biol Chem 1988; 263: 12801-12804.

99. Farin CE, Imakawa K, Roberts RM. In situ localization of mRNA for the interferon, ovine trophoblast protein-1, during early embryonic development of the sheep. Mol Endocrinol 1989; 3: 1099-1107.

100. Guillomot M, Michel C, Gaye P, Charlier N, Trojan J, Martal J. Cellular localization of an embryonic interferon, ovine trophoblastin and its mRNA in sheep embryos during early pregnancy. Biol Cell 1990; 68: 205-211.

101. Ashworth CJ, Bazer FW. Changes in ovine conceptus and endometrial function following asynchronous embryo transfer or administration of progesterone. Biol Reprod 1989; 40: 425-433.

102. Imakawa K, Hansen TR, Malathy PV, Anthony RV, Polites HG, Marotti KR, Roberts RM. Molecular cloning and characterization of complementary deoxyribonucleic acids corresponding to bovine trophoblast protein-1: A comparison with ovine trophoblast protein-1 and bovine interferon- $\alpha_{\text {II }}$. Mol Endocrinol 1989; 3: 127139.

103. McCracken JA, Barcikowski B, Carlson JC, Green K, Samuelsson B. The physiological role of prostaglandin $\mathrm{F}_{2 \alpha}$ in corpus luteum regression. Adv Biosci 1973; 9: 599-624.

104. Goding JR. The demonstration that PGF2 is the uterine luteolysin in the ewe. J Reprod Fertil 1974; 38: 261-271.

105. Godkin JD, Bazer FW, Roberts RM. Ovine trophoblast protein 1, an early secreted blastocyst protein, binds specifically to uterine endometrium and affects protein synthesis. Endocrinology 1984; 114: 120-130.

106. Stewart HJ, McCann SH, Barker PJ, Lee KE, Lamming GE, Flint AP. Interferon sequence homology and receptor binding activity of ovine trophoblast antiluteolytic protein. J Endocrinol 1987; 115: R13-R15.

107. Li J, Roberts RM. Structure-function relationships in the interferon- $\tau$ (IFN- $\tau$ ). Changes in receptor binding and in antiviral and antiproliferative activities resulting from site-directed mutagenesis performed near the carboxyl terminus. J Biol Chem 1994; 269: 24826-24833.
108. Spencer TE, Ing NH, Ott TL, Mayes JS, Becker WC, Watson GH, Mirando MA, Bazer FW. Intrauterine injection of ovine interferon-tau $(\mathrm{oIFN} \tau)$ alters oestrogen receptor and oxytocin receptor expression in the endometrium of cyclic ewes. J Mol Endocrinol 1995; 15: 203-220.

109. Spencer TE, Becker WC, George P, Mirando MA, Ogle TF, Bazer FW. Ovine interferon- $\tau$ inhibits estrogen receptor up-regulation and estrogeninduced luteolysis in cyclic ewes. Endocrinology 1995; 136: 4932-4944.

110. Spencer TE, Bazer FW. Ovine interferon- $\tau$ suppresses transcription of the estrogen receptor and oxytocin receptor genes in the ovine endometrium. Endocrinology 1996; 137: 1144-1147.

111. Hernandez-Ledezma JJ, Sikes JD, Murphy CN, Watson AJ, Schultz GA, Roberts RM. Expression of bovine trophoblast interferon in conceptuses derived by in vitro techniques. Biol Reprod 1992; 47: 374-380.

112. Imakawa K, Helmer SD, Nephew KP, Meka CSR, Christenson RK. A novel role for GM-CSF: Enhancement of pregnancy specific interferon production, ovine trophoblast protein-1. Endocrinology 1993; 132: 1869-1871.

113. Imakawa K, Tamura K, McGuire WJ, Khan S, Harbison LA, Stanga JP, Helmer SD, Christenson RK. Effect of interleukin-3 on ovine trophoblast interferon during early conceptus development. Endocrine 1995; 3: 511-517.

114. McGuire WJ, Imakawa K, Tamura K, Meka CS, Christenson RK. Regulation of endometrial granulocyte macrophage-colony stimulating factor (GM-CSF) in the ewe. Domest Anim Endocrinol 2002; 23: 383-396.

115. Imakawa K, Carlson KD, McGuire WJ, Christenson RK, Taylor A. Enhancement of ovine trophoblast interferon by granulocyte macrophagecolony stimulating factor: Possible involvement of protein kinase C. J Mol Endocrinol 1997; 19: 121-130.

116. Yamaguchi H, Ikeda Y, Moreno JI, Katsumura M, Miyazawa T, Takahashi E, Imakawa K, Sakai S, Christenson RK. Identification of a functional transcriptional factor AP-1 site in the sheep interferon $\tau$ gene that mediates a response to PMA in JEG3 cells. Biochem J 1999; 340: 767-773.

117. Ezashi T, Ealy AD, Ostrowski MC, Roberts RM. Control of interferon gene expression by Ets-2. Proc Natl Acad Sci USA 1998; 95: 7882-7887.

118. Xu N, Takahashi Y, Matsuda F, Sakai S, Christenson RK, Imakawa K. Coactivator CBP in the regulation of conceptus IFN $\tau$ gene transcription. Mol Reprod Dev 2003; 65: 23-29.

119. Ezashi T, Ghosh D, Roberts RM. Repression of Ets2-induced transactivation of the tau interferon promoter by Oct-4. Mol Cell Biol 2001; 21: 7883-7891. 